
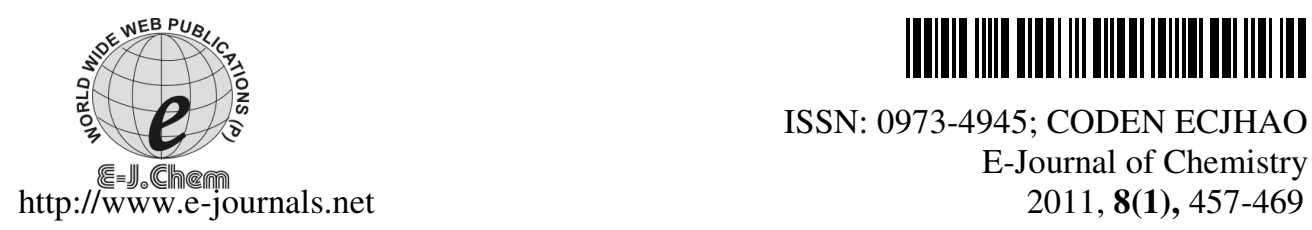

ISSN: 0973-4945; CODEN ECJHAO

E-Journal of Chemistry

2011, 8(1), 457-469

\title{
Ultrasonic Investigations of Molecular Interaction in Binary Mixtures of Benzyl Benzoate with Acetonitrile and Benzonitrile
}

\author{
N. JAYA MADHURI, P.S. NAIDU*, \\ J. GLORY and K. RAVINDRA PRASAD \\ Department of Physics, S.V.U.P.G.Centre, Kavali-524 201, India \\ psnaidujb@yahoo.co.in
}

Received 22 May 2010; Accepted 23 July 2010

\begin{abstract}
Ultrasonic velocity, density and viscosity have been measured in the binary mixtures of benzyl benzoate with acetonitrile, benzonitrile at three temperatures 30, 40 and $50{ }^{\circ} \mathrm{C}$. From the experimental data, thermodynamic parameters like adiabatic compressibility, internal pressure, enthalpy, activation energy etc., were computed and the molecular interactions were predicted based on the variation of excess parameters in the mixture. Also theoretical evaluation of velocities was made employing the standard theories. CFT and NOMOTO were found to have an edge. All the three mixtures have shown out strong intermolecular interactions between the unlike molecules and endothermic type of chemical reaction.
\end{abstract}

Keywords: Ultrasonic velocity, Benzyl benzoate, Internal pressure, Activation energy, Compressibility, Binary mixtures.

\section{Introduction}

The work on medicinally used chemical compounds requires the attention of the society in all aspects including ultrasonic behaviour. Practically, ultrasonic studies are of immense use to study the molecular interactions when these compounds are in binary mixture form with some other liquids - protic /aprotic /polar /nonpolar etc. Benzyl benzoate is a carboxylate ester which is used as an insect repellant, a medicine for scabies and also used in oily injections. Behaviour of benzyl benzoate in many liquids such as aliphatic alkanes, aromatic alkanes, aliphatic alcohols, substituted benzenes, acetates, ketones and DMSO (super solvent $)^{1-4}$ has been thoroughly studies ultrasonically.

In the present investigation, it is aimed at a detailed study of the binary mixture of benzyl benzoate with two nitriles - acetonitrile and benzonitrile at three temperatures 30, 40 and $50{ }^{\circ} \mathrm{C}$. From the experimentally measured data of velocity, density and viscosity, thermodynamic and other related parameters like adiabatic compressibility, internal pressure, 
activation energy etc., are computed and in terms of their excess parameters, the nature of molecular interactions is predicted in the binary mixtures. Also an evaluation of velocities using five theories is attempted. CFT, NOMOTO and JUNJIE have shown an edge.

\section{Experimental}

The chemicals used in the present investigation are of analar grade and are further purified by employing the standard methods mentioned in literature ${ }^{5}$. The binary mixtures were prepared by mixing the weighed quantities of the pure liquids. Ultrasonic velocity was measured using a single crystal interferometer working at $2 \mathrm{MHz}$ with an accuracy of $\pm 0.05 \%$. Density has been measured employing a double stem capillary type pyknometer with an accuracy of 2 parts in $10^{5}$. Weights were taken using an electronic single pan balance with an accuracy of $\pm 0.05 \mathrm{mg}$. Ostwald viscometer yielding an accuracy of $\pm 0.1 \%$ has been employed for viscosity measurements. Temperature was maintained to within $\pm 0.01 \mathrm{~K}$ employing an electronically controlled water bath. All the three measuring devices-interferometer, pyknometer and viscometer were standardized with triply distilled water as reference liquid before carrying out all the measurements in the test liquids.

\section{Theoretical details}

All the thermodynamic and related parameters were computed from the following relations ${ }^{6-9}$.

$$
\begin{aligned}
& \text { Adiabatic Compressibility } \quad \beta=\frac{1}{\mathrm{U}_{\exp }^{2} \rho_{\exp }} \\
& \text { Internal pressure } \pi=\mathrm{bRT}[\mathrm{K} \eta / \mathrm{U}]^{3 / 2} \rho^{2 / 3} / \mathrm{M}_{\mathrm{eff}}{ }^{7 / 6} \\
& \text { Free volume } V_{f}=\left(M_{\text {eff }} U / K \eta\right)^{3 / 2} \\
& \text { Enthalpy . } \mathrm{H}=\pi \mathrm{V}_{\mathrm{M}} \\
& \text { Activation Energy } G=R T\left[\ln \eta V_{M}\right]
\end{aligned}
$$

All the excess parameters are computed using the general formula

$$
A_{\text {excess }}=A_{\text {expt }}-A_{\text {ideal }}=\left[A_{\text {expt }}-\left(X_{1} A_{1}+X_{2} A_{2}\right)\right]
$$

$A$ is any parameter and $X_{1}$ and $X_{2}$ are the mole fractions of components 1 and 2 respectively.

\section{Results and Discussion}

Ultrasonic velocity, density and viscosity have been measured in the binary systems of benzyl benzoate with the liquids - acetonitrile, benzonitrile at three temperatures 30, 40 and $50{ }^{\circ} \mathrm{C}$ over the entire composition range. Using the standard relations (appended) explained elsewhere, thermodynamic and other allied parameters like adiabatic compressibility, free length, internal pressure, enthalpy, activation energy etc., have been computed and in terms of their excess parameters, molecular interactions have been predicted / estimated. Detailed presentation of results, analysis and interpretation are presented for all the three binary mixtures separately and a comparison is made at the end. Also velocities have been evaluated theoretically employing the five theories - FLT, CFT, NOMOTO, VANDAEL \& JUNJIE, the details of the theories and method of calculation are given elsewhere ${ }^{10}$.

\section{Benzyl benzoate + acetonitrile}

Experimentally measured velocity, density and viscosity data as a function of the mole fraction of benzyl benzoate at three different temperatures 30,40 and $50{ }^{\circ} \mathrm{C}$ in the binary mixture: benzyl benzoate + acetonitrile have been presented in Table 1. It can be observed that 
velocity increases from acetonitrile to benzoate and velocity decreases with temperature at all concentrations. Velocities have also been evaluated theoretically employing the five theories FLT, CFT, NOMOTO, VANDAEL \& JUNJIE. On comparing them with the experimental velocities, the maximum $\%$ deviations at $30{ }^{\circ} \mathrm{C}$ noticed were $-9.02,-3.49,1.44,-24.60$ and 1.04 respectively. From this one infers that CFT, JUNJIE and NOMOTO agree well with the experiment while VANDAEL shows larger deviations with temperature deviations decrease.

Table 1. Ultrasonic velocities, densities and viscosities for the system benzyl benzoate in benzyl benzoate + acetonitrile

\begin{tabular}{|c|c|c|c|}
\hline $\begin{array}{l}\text { Mole fraction of } \\
\text { Benzyl benzoate }\end{array}$ & $\begin{array}{c}\text { Velocity, } \\
\mathrm{ms}^{-1}\end{array}$ & $\begin{array}{l}\text { Density, } \\
\mathrm{k} \mathrm{gm}^{-3}\end{array}$ & $\begin{array}{l}\text { Viscosity, } \\
\text { milli Pa.s }\end{array}$ \\
\hline \multicolumn{4}{|c|}{$30{ }^{\circ} \mathrm{C}$} \\
\hline 0.0000 & 1261.9 & 773.01 & 0.36542 \\
\hline 0.0272 & 1284.0 & 828.61 & 0.41306 \\
\hline 0.0563 & 1296.0 & 855.66 & 0.49139 \\
\hline 0.1438 & 1335.6 & 907.40 & 0.72025 \\
\hline 0.2013 & 1360.8 & 946.05 & 0.90228 \\
\hline 0.2743 & 1381.2 & 976.17 & 1.16901 \\
\hline 0.3702 & 1404.0 & 1004.20 & 1.57945 \\
\hline 0.4362 & 1418.0 & 1026.15 & 1.87432 \\
\hline 0.5563 & 1440.8 & 1044.14 & 2.41858 \\
\hline 0.6939 & 1456.8 & 1077.72 & 3.00453 \\
\hline 0.8425 & 1480.0 & 1097.43 & 3.78936 \\
\hline 1.0000 & 1506.0 & 1119.35 & 6.53251 \\
\hline \multicolumn{4}{|c|}{$40{ }^{0} \mathrm{C}$} \\
\hline 0.0000 & 1226.4 & 763.31 & 0.32902 \\
\hline 0.0272 & 1254.0 & 821.46 & 0.40206 \\
\hline 0.0563 & 1272.0 & 846.14 & 0.47239 \\
\hline 0.1438 & 1302.0 & 900.78 & 0.67779 \\
\hline 0.2013 & 1326.0 & 944.54 & 0.85254 \\
\hline 0.2743 & 1344.0 & 968.07 & 1.08209 \\
\hline 0.3702 & 1374.0 & 995.87 & 1.42204 \\
\hline 0.4362 & 1392.0 & 1020.20 & 1.67381 \\
\hline 0.5563 & 1410.3 & 1031.84 & 2.10723 \\
\hline 0.6939 & 1428.0 & 1046.44 & 2.68134 \\
\hline 0.8425 & 1449.0 & 1076.94 & 3.35617 \\
\hline 1.0000 & 1471.4 & 1109.77 & 5.02109 \\
\hline \multicolumn{4}{|c|}{$50{ }^{0} \mathrm{C}$} \\
\hline 0.0000 & 1173.4 & 751.79 & 0.30662 \\
\hline 0.0272 & 1212.0 & 832.23 & 0.38438 \\
\hline 0.0563 & 1236.0 & 845.22 & 0.44867 \\
\hline 0.1438 & 1268.0 & 899.25 & 0.63785 \\
\hline 0.2013 & 1293.6 & 939.11 & 0.79138 \\
\hline 0.2743 & 1312.0 & 967.02 & 1.00003 \\
\hline 0.3702 & 1344.0 & 997.53 & 1.26843 \\
\hline 0.4362 & 1362.0 & 1012.76 & 1.40347 \\
\hline 0.5563 & 1375.9 & 1031.65 & 1.81713 \\
\hline 0.6939 & 1392.0 & 1050.04 & 2.27957 \\
\hline 0.8425 & 1414.9 & 1076.32 & 2.90921 \\
\hline 1.0000 & 1440.0 & 1070.90 & 4.29834 \\
\hline
\end{tabular}


The thermodynamic and other related parameters computed are shown in Table 2. Adiabatic compressibility $(\beta)$, free length $\left(L_{f}\right)$ and internal pressure $(\pi)$ decrease with concentration of benzyl benzoate while parameters like enthalpy $(\mathrm{H})$ and activation energy (G) increase. All the parameters decrease with temperature. But for a better understanding of the molecular interactions in the mixture, excess parameters computed are delineated from Figures 1(a) - 1(f). As observed from Figures, $\beta^{\mathrm{E}}$ and $\mathrm{L}_{\mathrm{f}}^{\mathrm{E}}$ are negative through out the concentration at all temperatures, with a minimum around $0.3 \mathrm{~m}$. With rise in temperature, they are more negative (slightly positive at higher concentration $\beta^{\mathrm{E}}$ at $50{ }^{\circ} \mathrm{C}$ ).

Table 2. Various parameters adiabatic compressibility, internal pressure, free volume, freelength, enthalpy and activation energy as a function of mole fraction of benzyl benzoate in benzyl benzoate + acetonitrile

\begin{tabular}{|c|c|c|c|c|c|c|}
\hline $\begin{array}{l}\text { Mole } \\
\text { Fraction } \\
\text { of BB }\end{array}$ & $\begin{array}{c}\text { Adiabatic } \\
\text { Compressibility, } \\
10^{10} \mathrm{~N}^{-1} \mathrm{~m}^{2} \\
\end{array}$ & $\begin{array}{c}\text { Internal } \\
\text { Pressure, } \\
\text { atm }\end{array}$ & $\begin{array}{c}\text { Molar } \\
\text { Volume, } \\
10^{-3} \text { L.mole }^{-1}\end{array}$ & $\begin{array}{c}\text { Free } \\
\text { Length, } \\
A^{0}\end{array}$ & $\begin{array}{l}\text { Enthalpy, } \\
\text { kJ mole }^{-1}\end{array}$ & $\begin{array}{c}\text { Gibb's } \\
\text { Energy } \\
\text { (RT units) }\end{array}$ \\
\hline & & & $30^{\circ} \mathrm{C}$ & & & \\
\hline 0.0000 & 8.12 & 5445 & 53.10 & 0.5687 & 289 & 2.97 \\
\hline 0.0272 & 7.32 & 5302 & 55.17 & 0.5399 & 293 & 3.13 \\
\hline 0.0563 & 6.96 & 5153 & 59.83 & 0.5263 & 308 & 3.38 \\
\hline 0.1438 & 6.18 & 4780 & 72.37 & 0.4960 & 346 & 3.95 \\
\hline 0.2013 & 5.71 & 4630 & 79.81 & 0.4767 & 369 & 4.28 \\
\hline 0.2743 & 5.37 & 4468 & 90.15 & 0.4624 & 403 & 4.66 \\
\hline 0.3702 & 5.05 & 4299 & 104.00 & 0.4485 & 447 & 5.10 \\
\hline 0.4362 & 4.85 & 4194 & 112.77 & 0.4393 & 473 & 5.35 \\
\hline 0.5563 & 4.61 & 3951 & 130.53 & 0.4286 & 516 & 5.75 \\
\hline 0.6939 & 4.37 & 3713 & 148.32 & 0.4172 & 551 & 6.10 \\
\hline 0.8425 & 4.16 & 3525 & 168.84 & 0.4070 & 0.4070 & 595 \\
\hline 1.0000 & 3.94 & 3967 & $\begin{array}{l}189.62 \\
40^{\circ} \mathrm{C}\end{array}$ & 0.3960 & 752 & 752 \\
\hline 0.0000 & 8.71 & 5197 & 53.78 & 0.5889 & 280 & 2.87 \\
\hline 0.0272 & 7.74 & 2563 & 55.65 & 0.5552 & 292 & 3.11 \\
\hline 0.0563 & 7.30 & 5062 & 60.50 & 0.5393 & 306 & 3.35 \\
\hline 0.1438 & 6.55 & 4673 & 72.90 & 0.5106 & 341 & 3.90 \\
\hline 0.2013 & 6.02 & 4555 & 79.94 & 0.4896 & 364 & 4.22 \\
\hline 0.2743 & 5.72 & 4334 & 90.90 & 0.4772 & 394 & 4.59 \\
\hline 0.3702 & 5.32 & 4101 & 104.86 & 0.4602 & 430 & 5.00 \\
\hline 0.4362 & 5.06 & 3985 & 113.43 & 0.4488 & 452 & 5.25 \\
\hline 0.5563 & 4.87 & 3698 & 132.08 & 0.4405 & 488 & 5.63 \\
\hline 0.6939 & 4.69 & 3474 & 152.75 & 0.4319 & 531 & 6.01 \\
\hline 0.8425 & 4.42 & 3311 & 172.05 & 0.4196 & 570 & 6.36 \\
\hline 1.0000 & 4.16 & 3499 & $\begin{array}{c}191.26 \\
50^{0} \mathrm{C}\end{array}$ & 0.4071 & 669 & 6.87 \\
\hline 0.0000 & 9.66 & 5078 & 54.60 & 0.6202 & 277 & 2.82 \\
\hline 0.0272 & 8.18 & 5280 & 54.93 & 0.5707 & 290 & 3.05 \\
\hline 0.0563 & 7.74 & 4589 & 60.57 & 0.5553 & 303 & 3.30 \\
\hline 0.1438 & 6.92 & 4426 & 73.02 & 0.5248 & 335 & 3.84 \\
\hline 0.2013 & 6.36 & 4426 & 80.40 & 0.5034 & 356 & 4.15 \\
\hline 0.2743 & 6.01 & 4213 & 91.00 & 0.4891 & 383 & 4.51 \\
\hline 0.3702 & 5.55 & 3920 & 104.69 & 0.4701 & 410 & 4.89 \\
\hline 0.4362 & 5.32 & 3671 & 114.27 & 0.4604 & 419 & 5.08 \\
\hline 0.5563 & 5.12 & 3477 & 132.11 & 0.4515 & 459 & 5.48 \\
\hline 0.6939 & 4.91 & 3252 & 152.23 & 0.4424 & 495 & 5.85 \\
\hline 0.8425 & 4.64 & 3118 & 172.14 & 0.4299 & 537 & 6.22 \\
\hline 1.0000 & 4.36 & 3267 & 191.72 & 0.4165 & 626 & 6.71 \\
\hline
\end{tabular}




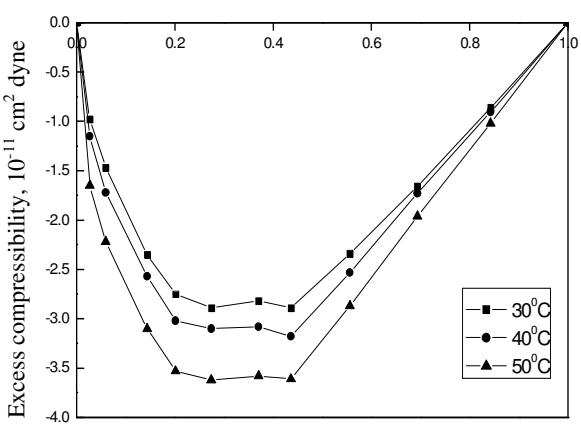

Mole fraction of benzyl benzoate

Figure 1a. Variation of excess adiabatic compressibility with mole fraction of benzyl benzoate in the mixture benzyl benzoate + acetonitrile

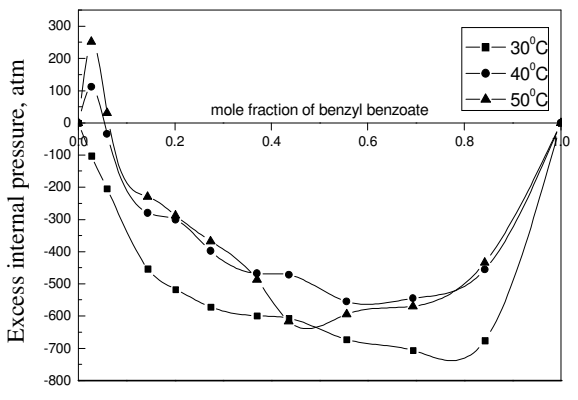

Mole fraction of benzyl benzoate

Figure 1c. Variation of excess internal pressure with mole fraction of benzyl benzoate in the mixture benzyl benzoate + acetonitrile

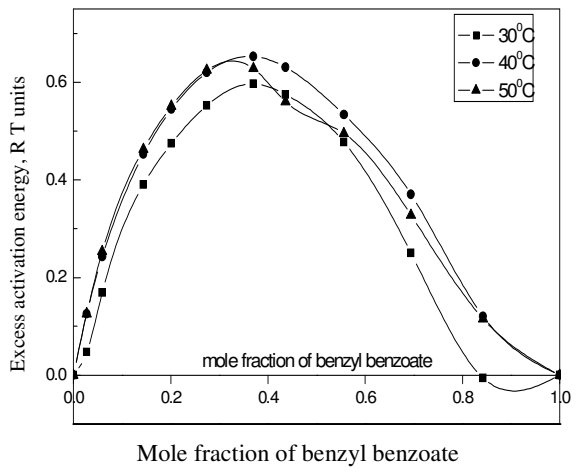

Figure 1e. Variation of excess activation energy with mole fraction of benzyl benzoate in the mixture benzyl benzoate + acetonitrile

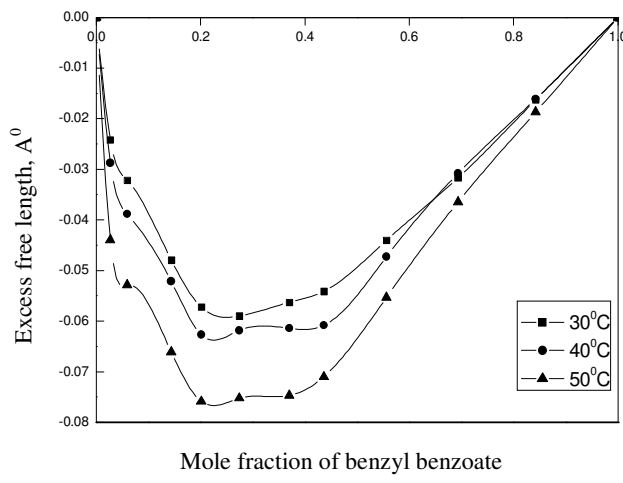

Figure 1b. Variation of excess free length with mole fraction of benzyl benzoate in the mixture benzyl benzoate + acetonitrile

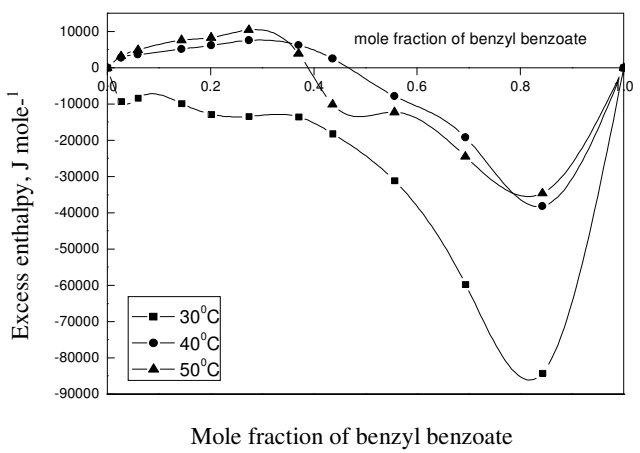

Figure 1d. Variation of excess enthalpy with mole fraction of benzyl benzoate in the mixture benzyl benzoate + acetonitrile

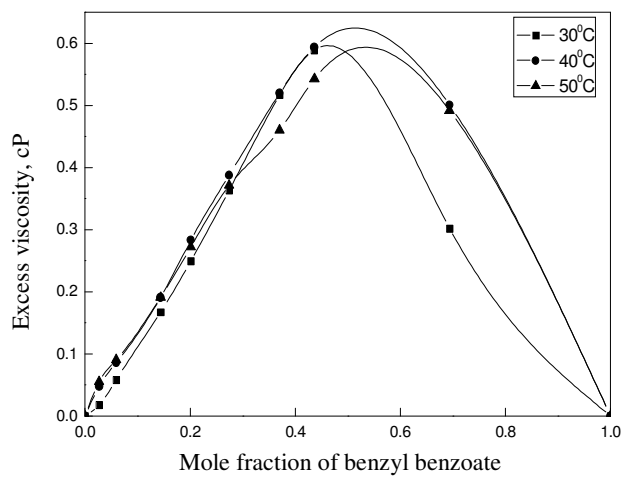

Figure 1f. Variation of excess viscosity with mole fraction of benzyl benzoate in the mixture benzyl benzoate + acetonitrile 
Systematic and regular variation noticed. $\pi^{\mathrm{E}}$ is also negative through out at all temperatures (except at $40 \& 50{ }^{\circ} \mathrm{C}$, at very low concentrations slightly positive). Excess enthalpy negative at $30{ }^{\circ} \mathrm{C}$, at all concentrations but positive up to $0.45 \mathrm{~m}$ and thereafter negative at 40 and $50{ }^{\circ} \mathrm{C}$. Both $\mathrm{G}^{\mathrm{E}}$ and $\eta^{\mathrm{E}}$ show positive variation throughout with maximum at around $0.45 \mathrm{~m}$ at all temperature, almost constant at high temperatures.

As most of the excess parameters are negative at all temperatures, it may be suggested that strong $\mathrm{AB}$ interactions and dipole-dipole type interactions are predominant. The strength of the interactions increases with temperatures as observed from more negative values of the excess parameters. From the positive $\mathrm{G}^{\mathrm{E}}$ and $\eta^{\mathrm{E}}$, endothermic type of chemical reaction is predicted through out the concentration range at all temperatures.

\section{Benzyl benzoate + benzonitrile}

Ultrasonic velocity, density and viscosity data measured experimentally as a function of mole fraction of benzyl benzoate at at three different temperatures 30,40 and $50{ }^{\circ} \mathrm{C}$ in the system: benzyl benzoate + benzonitrile is presented in Table 3 . In this system, velocity increases from benzonitrile to benzoate, the curve being slightly concave upwards and decreases with temperature. Theoretical evaluation of sound velocity using the already said five theories shows that here also CFT, NOMOTO and JUNJIE appear to have an edge (from the maximum $\%$ deviations $-3.07,-1.79,-0.37,-6.33,-0.51$ in the five theories respectively).

Table 3. Ultrasonic velocities, densities and viscosities for the system benzyl benzoate in Benzyl benzoate + benzonitrile

\begin{tabular}{lccc}
\hline $\begin{array}{c}\text { Mole fraction of } \\
\text { Benzyl benzoate }\end{array}$ & $\begin{array}{c}\text { Velocity } \\
\mathrm{ms}^{-1}\end{array}$ & $\begin{array}{c}\text { Density } \\
\mathrm{kgm}^{-3}\end{array}$ & $\begin{array}{c}\text { Viscosity, } \\
\text { milli Pa.s }\end{array}$ \\
\hline \multicolumn{2}{c}{$30^{0} \mathrm{C}$} & & \\
0.0000 & 1402.5 & 995.00 & 1.10441 \\
0.0354 & 1413.6 & 1009.32 & 1.27882 \\
0.1099 & 1422.0 & 1017.19 & 1.60421 \\
0.1747 & 1433.3 & 1032.81 & 1.89838 \\
0.2477 & 1446.0 & 1051.55 & 2.24881 \\
0.3306 & 1454.8 & 1067.41 & 2.74163 \\
0.4255 & 1466.8 & 1076.61 & 3.31420 \\
0.5354 & 1473.8 & 1083.68 & 3.82825 \\
0.6670 & 1485.5 & 1091.70 & 4.47007 \\
0.8160 & 1495.5 & 1110.45 & 4.92901 \\
0.9054 & 1501.8 & 1115.26 & 5.64283 \\
1.0000 & 1506.0 & 1119.35 & 6.53251 \\
& & $40{ }^{0} \mathrm{C}$ & \\
0.0000 & 1376.4 & 988.47 & 0.97315 \\
0.0345 & 1378.8 & 1003.86 & 1.18025 \\
0.1099 & 1398.0 & 1019.69 & 1.42016 \\
0.1747 & 1404.0 & 1028.17 & 1.64184 \\
0.2477 & 1414.8 & 1042.89 & 1.95808 \\
0.3306 & 1425.6 & 1054.18 & 2.38980 \\
0.4255 & 1438.0 & 1073.00 & 2.83100 \\
0.5354 & 1448.0 & 1078.78 & 3.16050 \\
0.6667 & 1453.5 & 1091.78 & 3.64468 \\
\hline & & & Contd...
\end{tabular}




\begin{tabular}{llll}
\hline 0.8160 & 1462.2 & 1102.86 & 4.23049 \\
0.9054 & 1470.8 & 1106.71 & 4.57659 \\
1.0000 & 1471.4 & 1109.77 & 5.02109 \\
0.0000 & 1327.2 & 977.07 & 1.50586 \\
0.0354 & 1351.2 & 990.67 & 1.86273 \\
0.1099 & 1362.0 & 1002.88 & 2.21078 \\
0.1747 & 1369.2 & 1020.25 & 2.61257 \\
0.2477 & 1378.8 & 1030.01 & 2.81251 \\
0.3306 & 1395.6 & 1046.63 & 3.31391 \\
0.4255 & 1410.0 & 1056.45 & 3.65646 \\
0.5354 & 1416.0 & 1062.30 & 3.83482 \\
0.6667 & 1422.9 & 1077.62 & 4.01543 \\
0.8160 & 1428.0 & 1091.47 & 4.03014 \\
0.9054 & 1433.4 & 1100.63 & 4.22971 \\
1.0000 & 1440.0 & 1070.90 & 4.29834 \\
\hline
\end{tabular}

Table 4 describes the variation of the thermodynamic parameters with concentration of benzyl benzoate. One can see that compressibility and free length decrease with concentration of benzoate at all temperatures and increase with temperature. Almost all other parameters $(\pi, \mathrm{H}, \mathrm{G}$ etc.,) increases with concentration and temperature as well.

Table 4. Various parameters adiabatic compressibility, internal pressure, free volume, freelength, enthalpy and activation energy as a function of mole fraction of benzyl benzoate in benzyl benzoate + benzonitrile

\begin{tabular}{|c|c|c|c|c|c|c|}
\hline $\begin{array}{l}\text { Mole } \\
\text { Fraction } \\
\text { of BB }\end{array}$ & $\begin{array}{c}\text { Adiabatic } \\
\text { Compressibility, } \\
10^{10} \mathrm{~N}^{-1} \mathrm{~m}^{2}\end{array}$ & $\begin{array}{c}\text { Internal } \\
\text { Pressure, } \\
\text { atm }\end{array}$ & $\begin{array}{c}\text { Molar } \\
\text { volume, } \\
10^{-3} \text { L.mole }^{-1}\end{array}$ & $\begin{array}{c}\text { Free } \\
\text { length, } \\
\mathrm{A}^{0}\end{array}$ & $\begin{array}{l}\text { Enthalpy, } \\
\mathrm{kJ} \text { mole }\end{array}$ & $\begin{array}{c}\text { Gibb's } \\
\text { energy } \\
\text { (RT units) }\end{array}$ \\
\hline & & & $30{ }^{\circ} \mathrm{C}$ & & & \\
\hline 0.000 & 5.11 & 3628 & 103.64 & 0.4510 & 376 & 4.74 \\
\hline 0.0354 & 4.96 & 3761 & 106.00 & .4443 & 399 & 4.91 \\
\hline 0.1099 & 4.86 & 3876 & 113.17 & 0.4400 & 439 & 5.20 \\
\hline 0.1747 & 4.71 & 3957 & 118.30 & .4332 & 468 & 5.41 \\
\hline 0.2477 & 4.55 & 4032 & 123.77 & 0.4255 & 499 & 5.63 \\
\hline 0.3306 & 4.43 & 4145 & 130.40 & 0.4199 & 540 & 5.88 \\
\hline 0.4255 & 4.32 & 4197 & 138.91 & 0.4146 & 583 & 6.13 \\
\hline 0.5354 & 4.25 & 4131 & 149.07 & 0.4113 & 616 & 6.35 \\
\hline 0.6670 & 4.15 & 4046 & 161.13 & 0.4065 & 652 & 6.58 \\
\hline 0.8160 & 4.03 & 3863 & 173.06 & 0.4004 & 668 & 6.75 \\
\hline 0.9054 & 3.98 & 3904 & 181.06 & 0.3979 & 707 & 6.93 \\
\hline 1.0000 & 3.94 & 3967 & $\begin{array}{l}189.62 \\
40^{0} \mathrm{C}\end{array}$ & 0.3960 & 752 & 7.12 \\
\hline 0.0000 & 5.34 & 3423 & 104.32 & 357 & 0.4611 & 4.62 \\
\hline 0.0354 & 5.24 & 3645 & 106.57 & 0.4568 & 388 & 4.83 \\
\hline 0.1099 & 5.02 & 3684 & 112.89 & 0.4470 & 416 & 5.08 \\
\hline 0.1747 & 4.93 & 3707 & 118.84 & 0.4432 & 441 & 5.27 \\
\hline 0.2477 & 4.79 & 3782 & 124.80 & 0.4367 & 472 & 5.50 \\
\hline 0.3306 & 4.67 & 3876 & 132.04 & 0.4311 & 512 & 5.75 \\
\hline 0.4255 & 4.51 & 3909 & 139.38 & 139.38 & 0.4236 & 545 \\
\hline
\end{tabular}




\begin{tabular}{lllllll}
\hline 0.5354 & 4.42 & 3776 & 149.75 & 0.4196 & 565 & 6.16 \\
0.6667 & 4.34 & 3694 & 161.09 & 0.4155 & 595 & 6.38 \\
0.8160 & 4.24 & 3603 & 174.24 & 0.4109 & 628 & 6.60 \\
0.9054 & 4.18 & 3535 & 182.46 & 0.4078 & 645 & 6.73 \\
1.0000 & 4.16 & 3499 & 191.26 & 0.4071 & 669 & 6.87 \\
& & & $50{ }^{0} \mathrm{C}$ & & & \\
0.0000 & 5.81 & 4302 & 105.54 & 0.4809 & 454 & 5.07 \\
0.0354 & 5.53 & 4585 & 107.99 & 0.4692 & 495 & 5.30 \\
0.1099 & 5.38 & 4605 & 114.79 & 0.4626 & 529 & 5.54 \\
0.1747 & 5.28 & 4712 & 119.73 & 0.4562 & 564 & 5.75 \\
0.2477 & 5.11 & 4554 & 126.36 & 0.4509 & 575 & 5.87 \\
0.3306 & 4.91 & 4592 & 132.99 & 0.4419 & 611 & 6.09 \\
0.4255 & 4.76 & 4440 & 141.57 & 0.4354 & 629 & 6.25 \\
0.5354 & 4.69 & 4163 & 152.07 & 0.4326 & 633 & 6.37 \\
0.6667 & 4.58 & 3885 & 163.21 & 0.4272 & 634 & 6.49 \\
0.8160 & 4.49 & 3534 & 176.07 & 0.4229 & 622 & 6.56 \\
0.9054 & 4.42 & 3429 & 183.46 & 0.4196 & 629 & 6.65 \\
1.0000 & 4.36 & 3267 & 191.72 & 0.4165 & 626 & 6.71 \\
\hline
\end{tabular}

But as already mentioned, to have a clear picture of the molecular interactions, the excess parameters have been computed and portrayed from Figures $2(a)-2(f) . \beta^{E}$ and $L_{f}^{E}$ behave similarly at all concentrations and temperatures. They are negative throughout with a minimum at $\sim 0.4 \mathrm{~m}$ and become more negative at all concentrations as the temperature is increased. As seen from Figure $2(\mathrm{c}), \pi^{\mathrm{E}}$ is positive up to $0.80 \mathrm{~m}$ and negative at higher concentrations at $30{ }^{\circ} \mathrm{C}$ and positive throughout at high temperatures. Similar trend is noticed in the variation of excess enthalpy $\left(\mathrm{H}^{\mathrm{E}}\right) . \mathrm{G}^{\mathrm{E}}$ is positive through out and becomes more positive at high temperatures with maximum at $\sim 0.4 \mathrm{~m} . \eta^{\mathrm{E}}$ is also similar to that of $\mathrm{G}^{\mathrm{E}}$ at all temperatures.

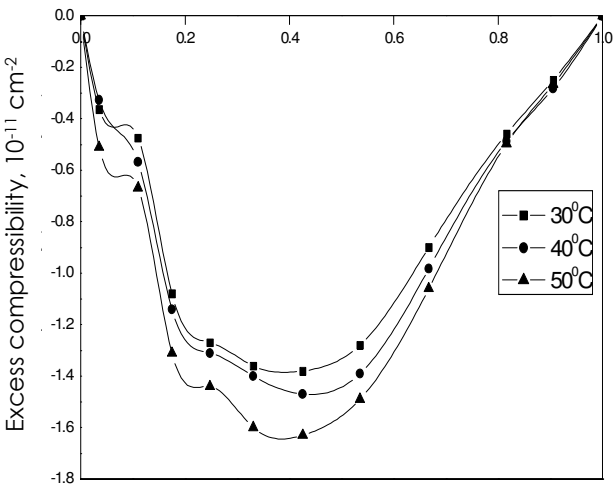

Mole fraction of benzyl benzoate

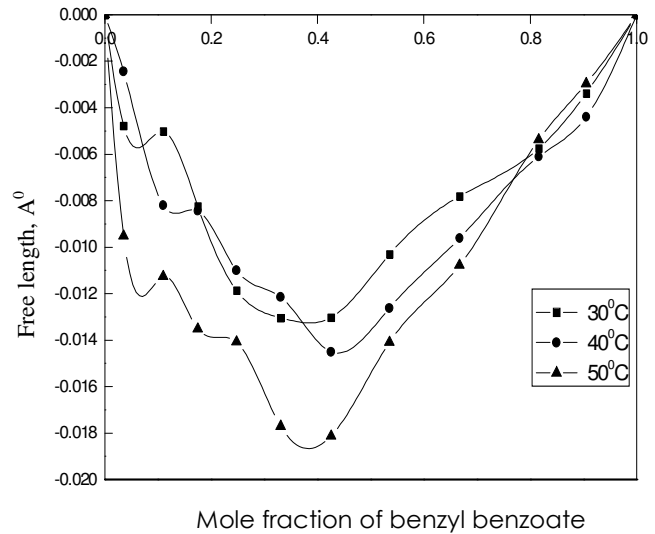

Figure 2b. Variation of excess free length with mole fraction of benzyl benzoate in the mixture benzyl benzoate + benzonitrile compressibility with mole fraction benzyl benzoate in the mixture benzyl benzoate + benzonitrile 


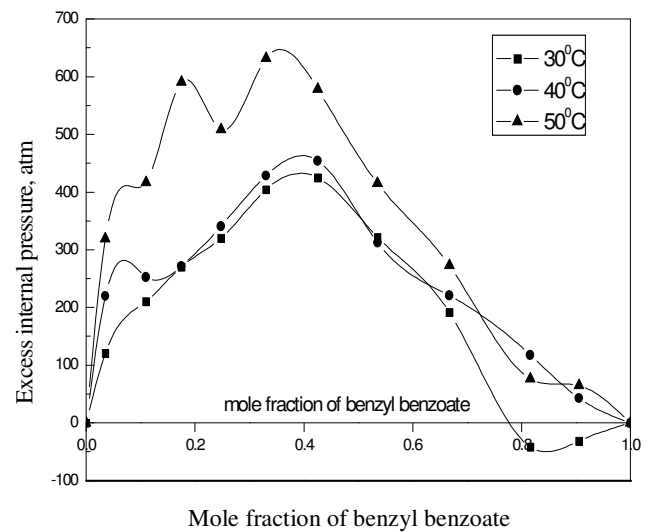

Figure 2c. Variation of excess internal pressure with mole fraction of benzyl benzoate in the mixture benzyl benzoate + benzonitrile

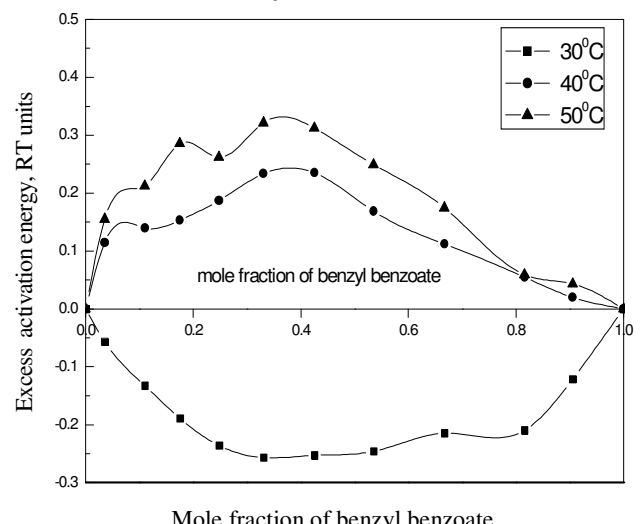

Figure 2e. Variation of excess activation energy with mole fraction of benzyl benzoate in the mixture benzyl benzoate + benzonitrile

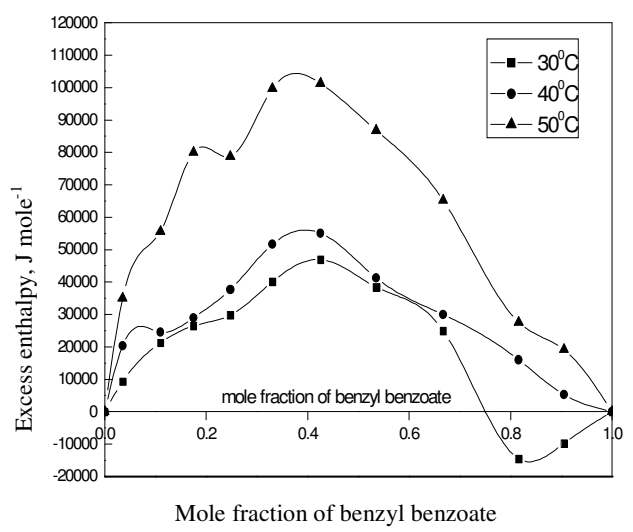

Figure 2d. Variation of excess enthalpy with mole fraction of benzyl benzoate in the mixture benzyl benzoate + benzonitrile

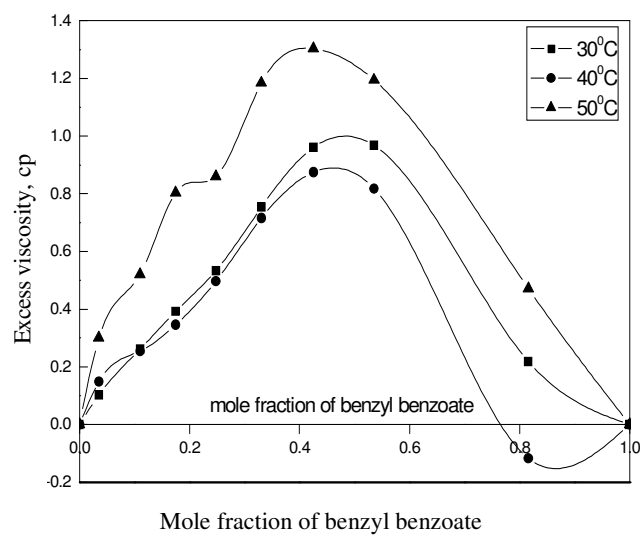

Figure 2f. Variation of excess viscosity with mole fraction of benzyl benzoate in the mixture benzyl benzoate + benzonitrile

Though $\mathrm{L}_{\mathrm{f}}^{\mathrm{E}}$ and $\beta^{\mathrm{E}}$ indicate strong $\mathrm{AB}$ interactions, the positive values of $\pi^{\mathrm{E}}$ and $\mathrm{H}^{\mathrm{E}}$ indicate weak interactions and dispersive forces at concentrations below $0.90 \mathrm{~m}$ while afterwards i.e., at high concentrations strong $\mathrm{AB}$ interactions are indicated at $30{ }^{\circ} \mathrm{C}$. At 40 and $50{ }^{\circ} \mathrm{C}$ totally weak interactions and dispersive forces result. From the positive values of $G^{E}$ and $\eta^{\mathrm{E}}$ mostly endothermic type of reaction is suggested in the mixture. Temperature variation shows the increase of the nature of reaction. The excess parameters are fitted to the Redlich - Kister type of $3^{\text {rd }}$ order polynomial and the coefficients are presented in Table 5. 
Table 5. Various parameters- $A_{0}, A_{1}, A_{2}, A_{3}$ along with standard deviation $\sigma$ using Redlich-kister method

\begin{tabular}{|c|c|c|c|c|c|c|c|c|c|c|c|c|c|c|c|c|c|c|c|c|c|}
\hline \multirow{2}{*}{$\begin{array}{l}\tilde{D} \\
\frac{ \pm}{\infty} \\
\dot{D}\end{array}$} & \multirow{2}{*}{ 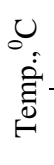 } & \multicolumn{5}{|c|}{$\beta^{\mathrm{E}}, 10^{-10} \mathrm{~m}^{2} \mathrm{~N}^{-1}$} & \multicolumn{5}{|c|}{$\pi^{\mathrm{E}}$, atm } & \multicolumn{5}{|c|}{$\mathrm{H}^{\mathrm{E}}, \mathrm{kJ} \mathrm{mole}^{-1}$} & \multicolumn{5}{|c|}{$\mathrm{G}^{\mathrm{E}},(\mathrm{RT}$ units $)$} \\
\hline & & $\mathrm{A}_{0}$ & $\mathrm{~A}_{1}$ & $\mathrm{~A}_{2}$ & $\mathrm{~A}_{3}$ & $\sigma$ & $\mathrm{A}_{0}$ & $\mathrm{~A}_{1}$ & $\mathrm{~A}_{2}$ & $\mathrm{~A}_{3}$ & $\sigma$ & $\mathrm{A}_{0}$ & $\mathrm{~A}_{1}$ & $\mathrm{~A}_{2}$ & $\mathrm{~A}_{3}$ & $\sigma$ & $\mathrm{A}_{0}$ & $\mathrm{~A}_{1}$ & $\mathrm{~A}_{2}$ & $\mathrm{~A}_{2}$ & $\sigma$ \\
\hline \multirow[t]{3}{*}{1} & 30 & -0.36 & -17.44 & 33.56 & -15.83 & 0.20 & -76 & -1948 & 522 & 1418 & 103 & -14 & 202 & -814 & 613 & 16 & -0.04 & 4.22 & -8.34 & 4.14 & 0.04 \\
\hline & 40 & -0.45 & -18.92 & 33.89 & -17.61 & 0.24 & 53 & -1791 & 499 & 1204 & 66 & -4 & 167 & -534 & 365 & 7 & 0.01 & 4.05 & -7.57 & 3.49 & 0.01 \\
\hline & 50 & -0.71 & -21.33 & 42.64 & -20.72 & 0.35 & 137 & -2235 & 871 & 1216 & 87 & -2 & 163 & -568 & 404 & 5 & 0.03 & 4.04 & -7.88 & 3.82 & 0.02 \\
\hline \multirow[t]{3}{*}{2} & 30 & 0.01 & -8.10 & -13.87 & -5.77 & 0.10 & -9 & 2761 & -5634 & 2843 & 50 & -3 & 302 & -605 & 298 & 9 & 0.01 & 2.18 & -3.86 & -1.67 & 0.03 \\
\hline & 40 & 0.02 & -8.50 & 14.32 & -5.83 & 0.08 & 53 & 2258 & -4278 & 1963 & 52 & 3 & 261 & -446 & 180 & 6 & 0.04 & 2.04 & -3.44 & -1.37 & 0.02 \\
\hline & 50 & -0.04 & -9.42 & 16.46 & -6.98 & 0.11 & 532 & 7046 & -16656 & 9181 & 285 & 53 & 896 & -187 & 937 & 29 & 0.28 & 4.34 & -9.13 & 4.56 & 0.15 \\
\hline
\end{tabular}

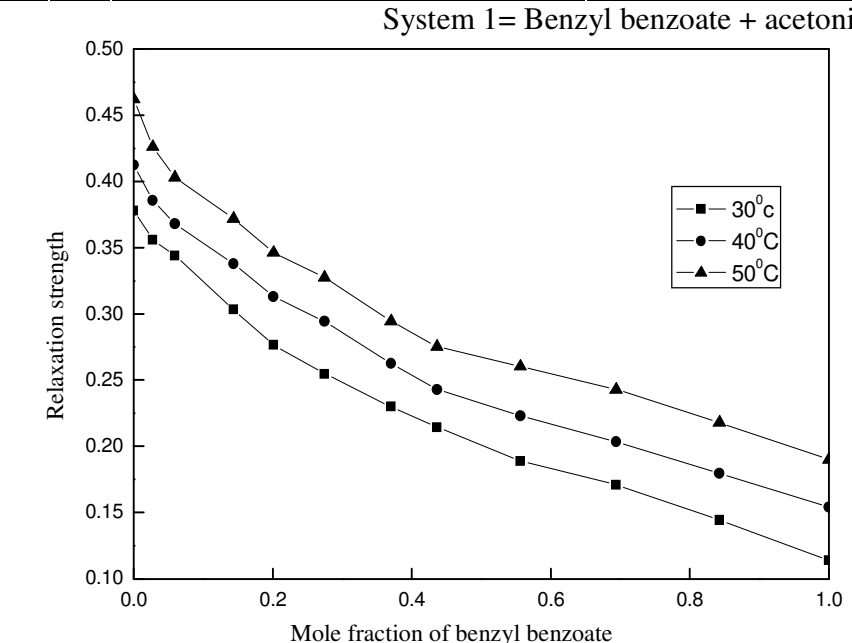

Figure 1(g). Variation of relaxation strength with mole fraction of benzyl benzoate in the mixture of benzyl benzoate+acetonitrile

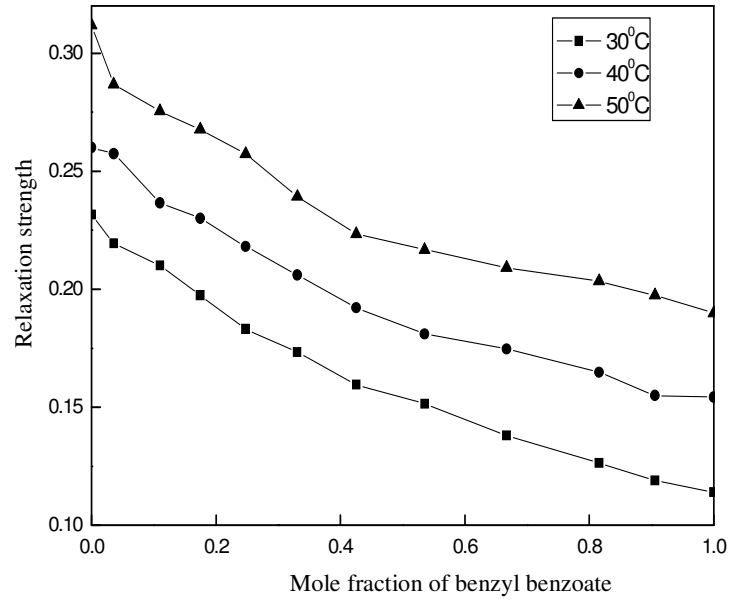

Figure 2(g). Variation of relaxation strength with mole fraction of benzyl benzoate in the mixture of benzyl benzoate+benzonitrile 


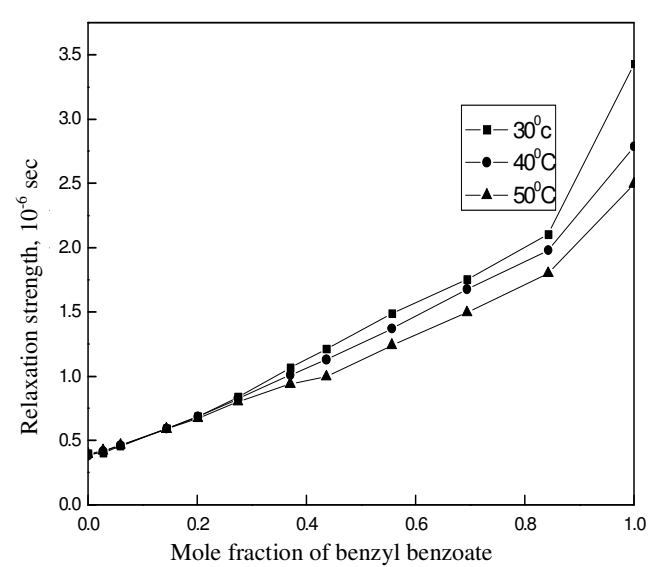

Figure 1(h). Variation of relaxation time with mole fraction of benzyl benzoate in the mixture of benzyl benzoate + acetonitrile

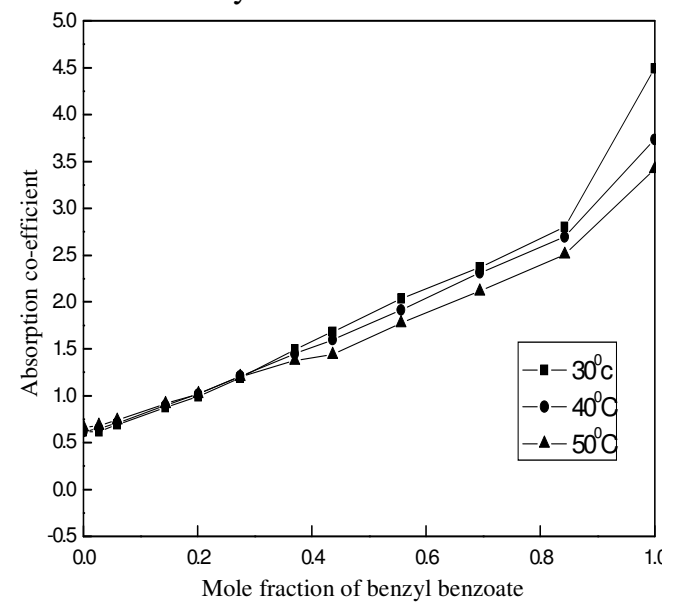

Figure 1(i). Variation of absorption coefficient with mole fraction of benzyl benzoate in the mixture of benzyl benzoate + acetonitrile

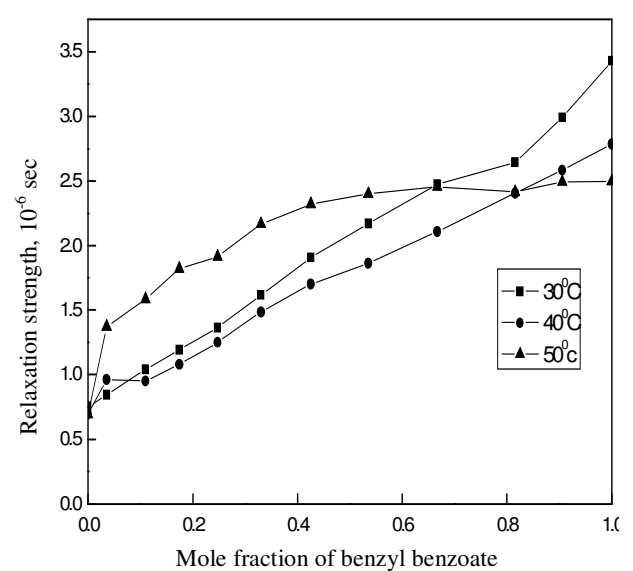

Figure 2(h). Variation of relaxation time with mole fraction of benzyl benzoate in the mixture of benzyl benzoate + benzonitrile

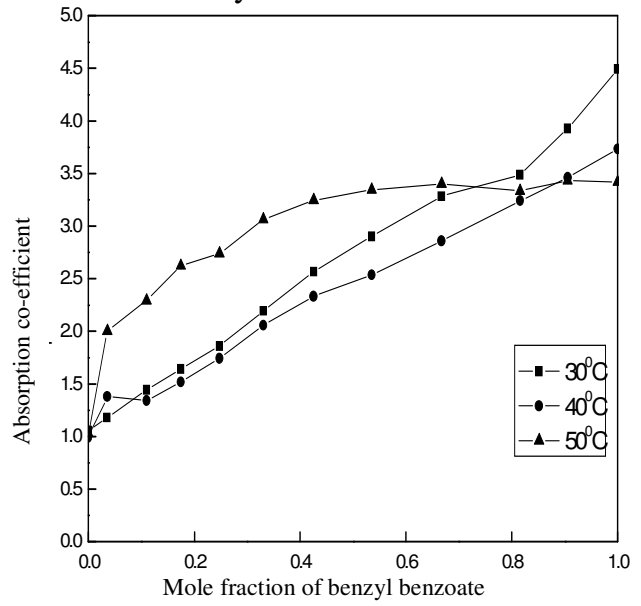

Figure 2(i). Variation of absorption coefficient with mole fraction of benzyl benzoate in the mixture of benzyl benzoate + benzonitrile

At this juncture, a comparison of our results with other results of benzoate is desired. In the solutions of benzyl benzoate in aliphatic alcohols, strong molecular interactions between unlike molecules are predicted besides dipole - dipole interactions. Endothermic reaction is suggested in all the systems. In the mixture of benzoate with aliphatic alkanes also, similar type of interactions are reported. In the mixtures of benzyl benzoate with acetones and ketones also similar interactions are predicted. In the mixtures of benzyl benzoate with acetones and ketones also similar interactions are predicted. In the two acetate systems (MAA and EA), presence of weak interaction besides dispersive forces is suggested and the effect increases from MAA to EA. In the two ketones - MEK and BMK systems also weak interactions are suggested and the strength of bonding further worsens from MEK to BMK 
i.e., by increase of molecular weight. Substituted benzenes like chloro, bromo and nitro benzenes yield similar results in benzyl benzoate.

Our results of the present investigation are in conformity with those of the above workers. Relaxation strength $\left(\alpha=1-\frac{U_{\text {exp }}^{2}}{U_{\infty}^{2}}\right)$, relaxation time $\left(\tau=\frac{4 \eta}{3 \rho U^{2}}\right)$ and classical absorption coefficient $\left(\left(\frac{\alpha}{f^{2}}\right)_{\text {classical }}=\frac{8 \pi^{2} \eta}{3 \rho U^{3}}\right)$ also have been computed using the mentioned standard relations ${ }^{11}$ from which the molecular interactions can also be estimated. Relaxation strength (Figures $1(\mathrm{~g})$ and $2(\mathrm{~g})$ ) decreases with concentration at all temperatures and increases with temperature at all concentrations of benzyl benzoate in both the systems which indicates the formation of aggregates of solvent molecules around the solute due to which structural arrangement is affected in the systems. Relaxation time (Figures 1(h) and 2(h)) and absorption coefficient (Figures 1(i) and 2(i)) increase with concentration of benzyl benzoate and temperature as well. In acetonitrile system up to $\sim 0.4 \mathrm{~m}$, the temperature variation of relaxation time and absorption is very very small while at higher concentrations, increase with temperature is conspicous and clear. The nature of molecular interactions from the behaviour of the above parameters is similar to the one obtained from the excess parameters.

The opposing tendencies (in various excess parameters) may be due to the fact that strong dipolar interactions and highly directional interaction bonding act simultaneously between the constituent molecules and the relationship between the excess functions is not simple and reflects the properties of the interaction molecules ${ }^{12}$. Also in a system it should be remembered that the effect of interaction between the like and unlike molecules balance each other in varying degrees.

Also for better understanding of the degree of interaction (magnitude etc.,) one requires all the theories FLT, CFT, H bond formation, dipole-dipole interactions etc. Such a comprehensive expression for intermolecular / atomic potential taking into account all the theories has not yet been worked out ${ }^{13}$.

\section{Acknowledgment}

The authors are thankful to the S.V.U.P.G. Centre authorities for providing the facilities to carry out this work.

\section{References}

1. Geetalakshmi M, Molecular interaction in the binary liquid mixtures-An ultrasonic study, M. Phil, dissertation submitted to Sri Venkateswara Univeristy, Tirupati 2006, India.

2. Geetalakshmi M, Naidu P S and Ravindra Prasad K, J Pure Appl Ultrason., 2008, 30(1), 18-23.

3. Sivasankar J, Geetalakshmi M, Naidu P S and Ravindra Prasad K, J Pure Appl Ultrason., 2007, 29(2-3), 82-88.

4. Ramesh P, Ultrasonic study of the binary liquid mixtures (Benzyl Benzoate + Substituted Benzenes), M.Phil, dissertation submitted to Sri Venkateswara Univeristy, Tirupati 2008, India.

5. Furniss B S, Hannaford A J, Rogers V S., Smith P W G and Tachell A R, Vogel's Text Book of Practical Organic chemistry, $4^{\text {th }}$ Edition, Longmann 1980.

6. Palaniappan L and Karthikeyan V, Indian J Phys., 2005, 79(2), 155. 
7. Nithya R, Mullainathan S, Nithiyanantham S and Rajasekaran M, E-J Chem., 2009, 6(1), 138-140.

8. Suryanarayana C V, J Acoust Soc India, 1983, 13, 9.

9. Mullainathan S and Nithyanantham S, E-J Chem., 2010, 7(2), 353-356.

10. Naidu P S, Prabhakara Rao N and Ravindra Prasad K, Indian J Pure Appl Ultrason., 2002, 24, 36.

11. Ravichandran S and Ramanadhan K, J Pure Appl Ultrason., 2006, 28, 40.

12. Ramanujappa T, Bhavani J A, Rajagopal E and Manohara Murthy N, Indian J Pure Appl Phys., 2000, 38, 301.

13. Yanadhi Reddy N, Subramanyam Naidu P and Ravindra Prasad K, Indian J Pure Appl Phys., 2004, 32, 958. 


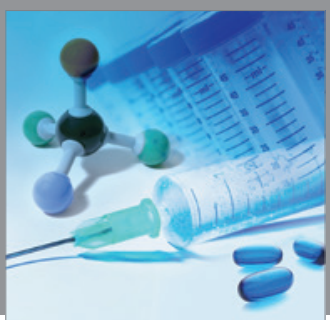

International Journal of

Medicinal Chemistry

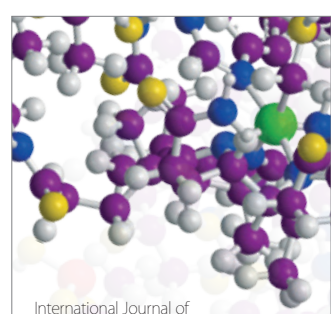

Carbohydrate Chemistry

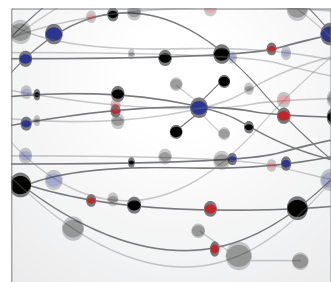

The Scientific World Journal
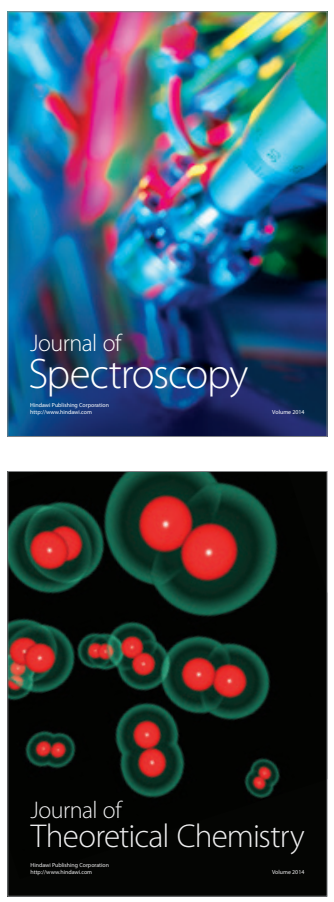
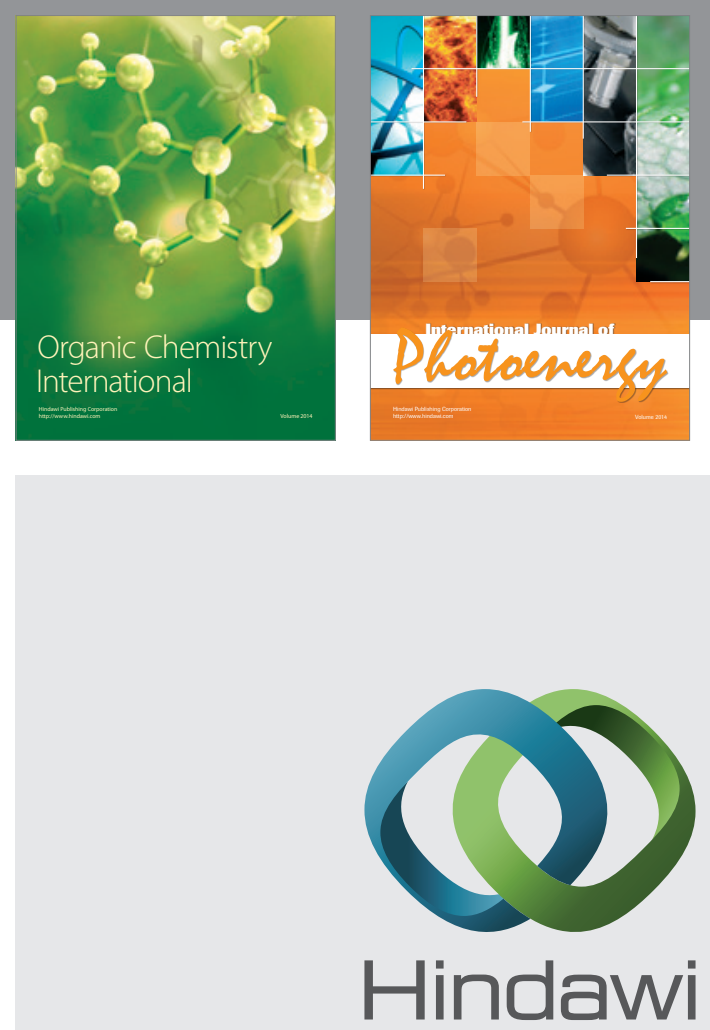

Submit your manuscripts at

http://www.hindawi.com
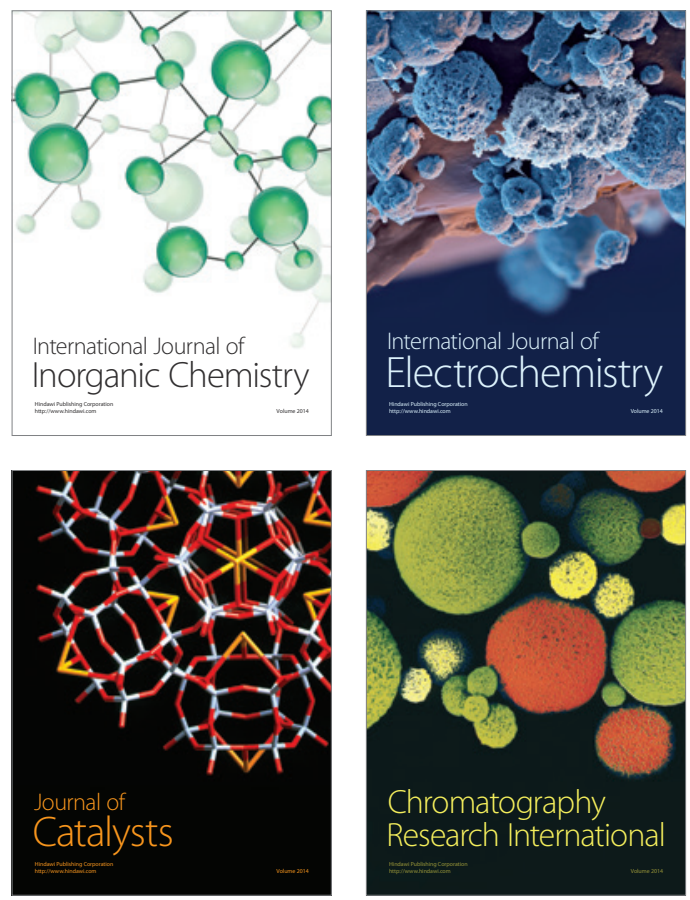
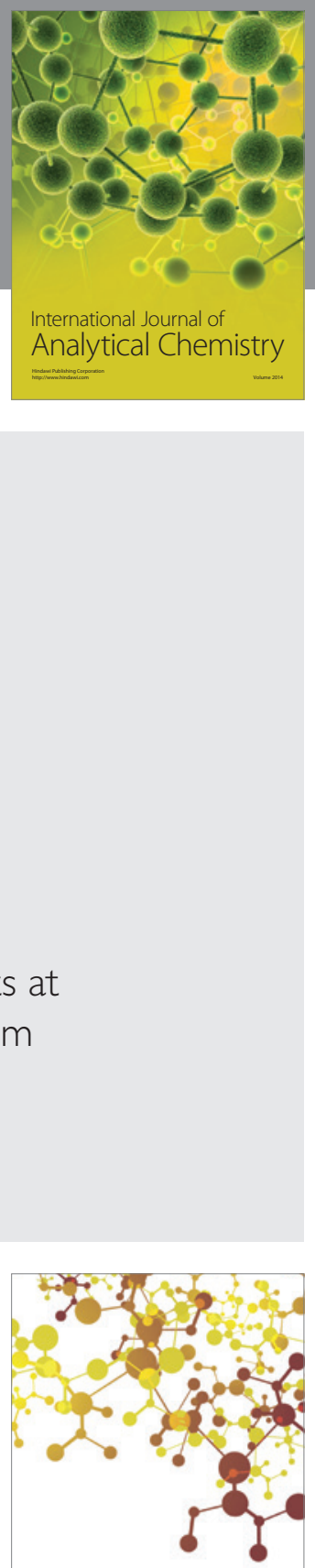

Journal of

Applied Chemistry
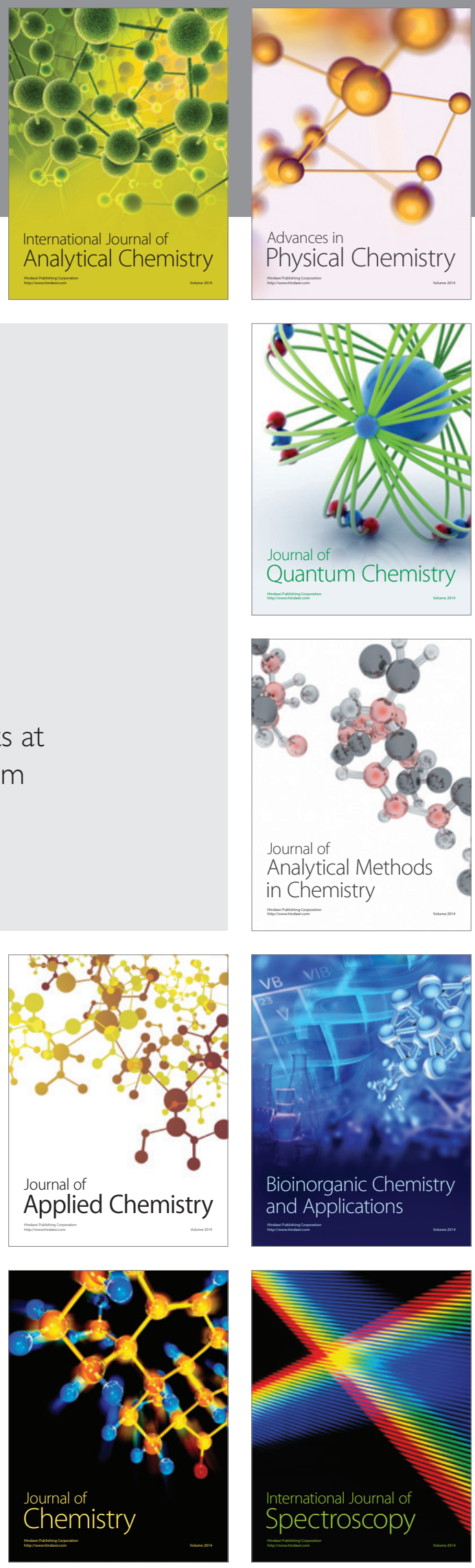